\title{
Radiological findings of COVID-19-related thromboembolic complications
}

\author{
Suzan Fouad Omar ${ }^{*}$ (D), Rehab Mohammed Habib and Abdelghany Mohammed Motawea
}

\begin{abstract}
Background: The ongoing global pandemic of coronavirus disease 2019 (COVID-19) may cause, in addition to lung disease, a wide spectrum of non-respiratory complications. Among these are thromboembolic complications. The theories that explain the mechanism of thromboembolic complications of COVID-19 are accumulating rapidly, and in addition to the role of imaging for assessment of COVID-19 pneumonia, CT may be useful for identification of these complications, such as pulmonary embolism, ischaemic stroke, mesenteric ischaemia, and acro-ischaemia.

Results: Thromboembolic manifestations were diagnosed in 10\% of our patients (124 patients out of the total 1245 COVID-19 patients); 56 patients (45.2\%) presented with pulmonary embolism, 32 patients (25.8\%) presented with cerebrovascular manifestations, 17 patients (13.7\%) presented with limb affection, and 19 patients (15.3\%) presented with gastrointestinal thromboembolic complications.

Most of our patients had significant comorbidities; diabetes was found in 72 patients (58\%), dyslipidemia in 72 patients (58\%), smoking in 71 patients (57.3\%), hypertension in 63 patients (50.8\%), and morbid obesity in 40 patients (32.2\%).

Thromboembolic events were diagnosed on admission in 41 patients (33.1\%), during the first week in 61 patients (49.2\%), and after the first week in 22 patients (17.7\%).

Conclusions: The incidence of thromboembolic complications in COVID-19 patients is relatively high resulting in a multisystem thrombotic disease. In addition to the crucial role of imaging for assessment of COVID-19 pneumonia, CT is important for assessment of the thromboembolic complications, such as pulmonary embolism, ischaemic stroke, mesenteric ischaemia, and peripheral ischaemia, especially in patients with elevated D-dimer levels and those with sudden clinical deterioration.
\end{abstract}

\section{Background}

The ongoing global pandemic of coronavirus disease 2019 (COVID-19) may cause, in addition to lung disease, a wide range of non-respiratory complications due to involvement of organs by the virus or due to direct or indirect complications of this infection [1, 2]. Among these, thromboembolic complications due to abnormal coagulation were presented as an important issue in patients with COVID-19 infection and may occur in up to $31 \%$ of COVID-19 patients in intensive care unit (ICU) $[3,4]$.

\footnotetext{
* Correspondence: suzan2012omar@gmail.com

Menofia University, Faculty of Medicine, Shebin El-Kom, Egypt
}

Other organ systems are affected due to the marked affinity of the virus for the angiotensin-converting enzyme 2 (ACE2) receptors $[5,6]$. Thus, tissues with high levels of ACE2 receptor are susceptible to direct infection [7]. These are most abundant in lung alveolar epithelial cells, enterocytes of the small intestine, and vascular endothelium [5].

Unlike hemorrhagic viruses (Ebola, Marburg...), Covid19 is highly prothrombotic causing alterations in the coagulation cascade that leads to a progressive elevation of D-dimer correlated with the severity and extent of microthrombosis [8].

There is increasing evidence that thrombi are a major cause of multisystem organ dysfunction, including respiratory failure [9]. A number of studies showed that

\section{Springer Open}

(0) The Author(s). 2021 Open Access This article is licensed under a Creative Commons Attribution 4.0 International License, which permits use, sharing, adaptation, distribution and reproduction in any medium or format, as long as you give appropriate credit to the original author(s) and the source, provide a link to the Creative Commons licence, and indicate if changes were made. The images or other third party material in this article are included in the article's Creative Commons licence, unless indicated otherwise in a credit line to the material. If material is not included in the article's Creative Commons licence and your intended use is not permitted by statutory regulation or exceeds the permitted use, you will need to obtain permission directly from the copyright holder. To view a copy of this licence, visit http://creativecommons.org/licenses/by/4.0/. 
coagulation disorders related to COVID-19 are correlated with increased morbidity and mortality $[10,11]$.

COVID-19-associated thrombotic disease is suggested to be caused by various mechanisms including direct effects of COVID-19 through severe illness and hypoxia or severe inflammatory response or an indirect effect of infection related to investigational therapies used for treating COVID-19, which may have adverse drug interactions with antiplatelet agents and anticoagulants [12].

The theories that explain the mechanism of thromboembolic complications of COVID-19 are accumulating rapidly, and in addition to the role of CT chest for assessment of COVID-19 pneumonia, other imaging modalities may be useful for identification of these complications, such as pulmonary embolism, ischaemic stroke, mesenteric ischaemia, and acro-ischaemia.

\section{Aim of this study}

The aim of this study was to estimate the prevalence of thromboembolic manifestations among COVID-19positive patients and to describe the imaging findings of Covid-19-positive patients who presented with acute arterial or venous thromboembolic events in the pulmonary, cerebral, abdominal, or peripheral circulation.

\section{Methods}

\section{Ethics approval and consent to participate}

The study protocol was approved by the local Ethics Committee. All study procedures were performed in accordance with the ethical standards laid down in the 1964 Declaration of Helsinki and its later amendments. The ethics committee's reference number is 9/2020RAD4.

All patients included in this study were informed that their clinical, laboratory, and radiological data will be used in the study. A written consent was taken from all patients.

\section{Study population}

Between April and July 2020, we scanned 1245 COVID19-positive patients, 124 of them (about 10\%) had developed thromboembolic manifestations, pulmonary, abdominal, cerebral, or peripheral limbs.

The study included 73 males (58.9\%) and 51 females (41.1\%) with age ranged from 23 to 65 years old, (mean age 43.52 years \pm 12.21 years).

Inclusion criteria included patients with confirmed Covid-19 infection who presented initially with thromboembolic symptoms or admitted to the hospital and then developed thromboembolic manifestations.

Exclusion criteria included patients with thromboembolic manifestations not confirmed to be COVID-19 positive and patients with chronic thromboembolic events.

\section{Imaging techniques}

Patients underwent imaging for the suspected region according to the primary manifestations. Patients with suspected stroke underwent MRI brain with DWI according to the routine stroke protocol. Positive patients with acute stroke underwent MR cerebral angiography and venography.

The CT pulmonary and abdominal angiogram was performed after intravenous injection of 80-120 cc of iodinated contrast media at a flow rate of $3-5 \mathrm{ml} / \mathrm{s}$ followed by a 30 $\mathrm{ml}$ saline at the same rate. Region of interest was determined, and axial scans were taken during the contrast injection until a threshold enhancement and triggering a diagnostic scan. Indirect venography was done for the patients.

Patients with suspected peripheral arterial or venous acute arterial and/or venous thrombosis underwent $\mathrm{du}$ plex/Doppler examination of the affected limb followed by CT peripheral angiography for positive cases.

All CT scans were performed on a 128-slice multidetector CT scanner.

\section{Image analysis}

The images were assessed for presence of vascular occlusion either arterial or venous.

Pulmonary CT angiography images were evaluated for location and extent of the thrombus, associated pulmonary manifestations of COVID-19, and presence of areas suggestive of lung infarction.

Abdominal CT angiography images were evaluated for evidence of arterial and/or venous thrombus (location and extent); involvement of IVC and portal, mesenteric, and iliac veins; and associated manifestations of bowel ischaemia (pneumatosis intestinale or portal vein gas) or intestinal obstruction. Evidence of solid organs infarction was evaluated.

Cerebral venogram and angiogram images were evaluated for location and extent of venous sinus thrombosis and evidence of acute arterial thrombosis and its location. Associated cerebral infarctions were evaluated for their extent and presence of hemorrhagic infarction. Evidence of diffusion restriction even with no definite vascular occlusion at angiography was considered thromboembolic events.

Duplex studies and peripheral angiography of the upper and lower limbs were evaluated for presence and extent of acute venous thrombosis and presence and extent of acute arterial occlusion.

\section{Data collection}

Demographic and clinical data (presenting symptoms, risk factors, D-dimer values, and ICU admission) were collected from medical records. All data were compiled and analyzed.

\section{Results}

This study is observational cross-sectional study included 1245 COVID-19-positive patients, 124 of them 


\section{Thromboembolic manifestations}

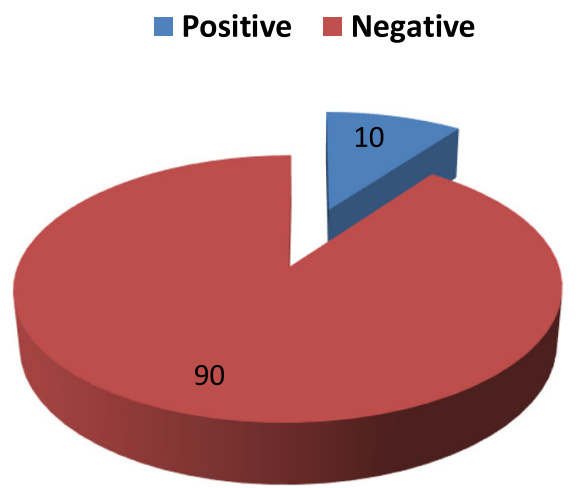

Fig. 1 Prevalence of thromboembolic manifestations among COVID-19-positive patients

(10\%) developed thromboembolic manifestations (Fig. 1). Fifty-six patients $(45.2 \%)$ had pulmonary embolism, 32 patients $(25.8 \%)$ had cerebrovascular manifestations, 17 patients $(13.7 \%)$ had peripheral vascular affection, and 19 patients (15.3\%) had gastrointestinal thromboembolic complications (Fig. 2).

Patients with thromboembolic manifestations were 77 males (62.1\%) and 47 females (37.9\%) with age ranged from 23 to 65 years old (mean age 43.52 years \pm 12.21 years). One or more comorbidities were found; diabetes was found in 72 patients (58\%), dyslipidemia in 72 patients $(58.1 \%)$, smoking in 71 patients $(57.3 \%)$, hypertension in 63 patients $(50.8 \%)$, and morbid obesity in 40 patients $(32.3 \%)$.
The D-dimer level was very high notably in patients with pulmonary embolism (Table 1). Thromboembolic events were diagnosed on admission in 41 patients (33.1\%), during the first week of admission in 61 patients (49.2\%), and after the first week of admission in 22 patients (17.7\%).

Pulmonary embolism presented on admission in 34 patients (60.7\%), 13 patients (23.2\%) developed symptoms within the first week of admission, and 9 patients (16.1\%) had pulmonary embolism after 1 week. The most presenting symptom was shortness of breath (52 patients $92.9 \%$ ). Fourteen patients were presented with radiological findings that favor the evidence of lung infarction more than the classic features of COVID-19 pneumonia.

Three patients $(9.4 \%)$ were presented with acute stroke. Twenty-four patients (75\%) developed cerebrovascular symptoms within the first week of hospital admission for respiratory manifestations. Five patients (15.6) developed cerebrovascular symptoms after 1 week of admission (2 patients presented with sensory manifestations and found to have small thalamic infarction and 3 patients developed motor deficit). Twenty-five patients (78.1\%) with cerebrovascular manifestations had associated pneumonia.

Ischaemic stroke has been associated with arterial thrombosis in 18 patients (40.6\%) and venous sinus thrombosis in 9 patients (25\%). Seven of them presented with hemorrhagic infarctions. Middle cerebral artery thrombosis was detected in 8 patients, internal carotid artery in 3 patients, anterior cerebral artery in 3 patients, basilar artery in 2 patients, and vertebral artery in 2 patients. Five patients (12.5\%) presented with small infarcts identified only on MRI with no definite vascular involvement. Superior sagittal sinus thrombosis was identified in 5 patients, sigmoid sinus thrombosis in 2

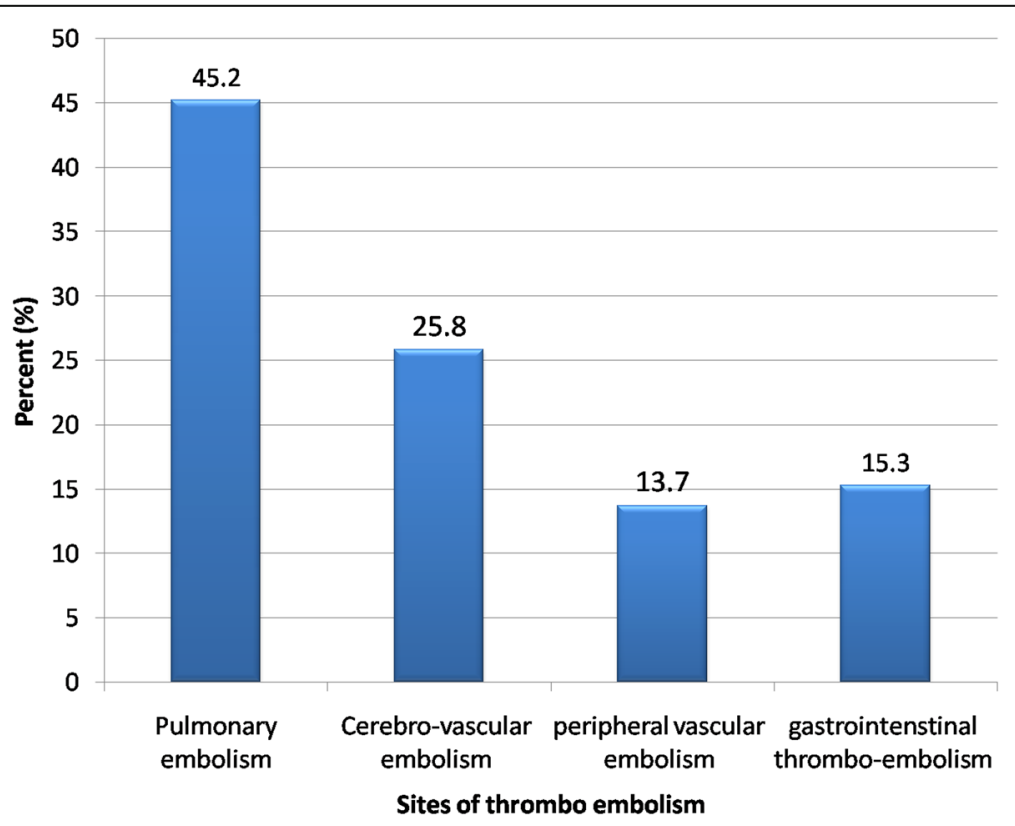

Fig. 2 Sites of thromboembolism among COVID-19 patients 
Table 1 Demographic data of the patients

\begin{tabular}{|c|c|c|c|c|c|c|c|c|c|c|c|}
\hline & \multicolumn{2}{|c|}{$\begin{array}{l}\text { Pulmonary } \\
(n=56)\end{array}$} & \multicolumn{2}{|c|}{$\begin{array}{l}\text { Cerebral } \\
(n=32)\end{array}$} & \multicolumn{2}{|c|}{$\begin{array}{l}\text { Peripheral } \\
(n=17)\end{array}$} & \multicolumn{2}{|c|}{$\begin{array}{l}\text { Abdominal } \\
(n=19)\end{array}$} & \multicolumn{2}{|c|}{$\begin{array}{l}\text { Total } \\
(n=124)\end{array}$} & \multirow[t]{2}{*}{$P$ value } \\
\hline & $N$ & $\%$ & $n$ & $\%$ & $n$ & $\%$ & $n$ & $\%$ & $n$ & $\%$ & \\
\hline Mean age & \multicolumn{2}{|c|}{$46.3 \pm 10.53$} & \multicolumn{2}{|c|}{$45 \pm 9.68$} & \multicolumn{2}{|c|}{$52.6 \pm 7.9$} & \multicolumn{2}{|c|}{$41.7 \pm 10.5$} & \multicolumn{2}{|c|}{$43.52 \pm 12.21$} & 0.01 \\
\hline \multicolumn{12}{|l|}{ Sex } \\
\hline Male & 37 & 66.1 & 20 & 62.5 & 12 & 70.6 & 8 & 42.1 & 77 & 62.1 & 0.25 \\
\hline Female & 19 & 33.9 & 12 & 37.5 & 5 & 29.4 & 11 & 57.9 & 47 & 37.9 & \\
\hline \multicolumn{12}{|l|}{ Risk factors } \\
\hline Hypertension & 28 & 50 & 23 & 71.9 & 6 & 35.3 & 6 & 31.6 & 63 & 50.8 & 0.017 \\
\hline Diabetes & 35 & 62.5 & 25 & 78.1 & 9 & 52.9 & 3 & 15.8 & 72 & 58.1 & $<0.001$ \\
\hline Dyslipidemia & 38 & 67.8 & 21 & 65.6 & 8 & 47.1 & 5 & 26.3 & 72 & 58.1 & 0.009 \\
\hline Smoking & 35 & 62.5 & 18 & 56.3 & 10 & 58.8 & 8 & 42.1 & 71 & 57.3 & 0.49 \\
\hline Morbid obesity & 15 & 26.7 & 11 & 34.4 & 6 & 35.3 & 8 & 42.1 & 40 & 32.3 & 0.63 \\
\hline Presence of pneumonia & 54 & 80.46 & 25 & 78.1 & 10 & 58.8 & 5 & 26.3 & 94 & 75.8 & $<0.001$ \\
\hline \multicolumn{12}{|l|}{ Day of presentation } \\
\hline On admission & 34 & 60.7 & 3 & 9.4 & 2 & 11.8 & 2 & 10.5 & 41 & 33.1 & $<0.001$ \\
\hline Within 1 week & 13 & 23.2 & 24 & 75 & 11 & 64.7 & 13 & 68.4 & 61 & 49.2 & \\
\hline After 1 week & 9 & 16.1 & 5 & 15.6 & 4 & 23.5 & 4 & 21.1 & 22 & 17.7 & \\
\hline ICU admission & 48 & 85.7 & 21 & 65.6 & 5 & 29.4 & 11 & 57.9 & 85 & 68.5 & $<0.001$ \\
\hline Hospital stay (average days) & \multicolumn{2}{|c|}{$22 \pm 3$} & \multicolumn{2}{|c|}{$18 \pm 1$} & \multicolumn{2}{|c|}{$11 \pm 2$} & \multicolumn{2}{|c|}{$14 \pm 4$} & \multicolumn{2}{|c|}{$18.9 \pm 3.7$} & $<0.001$ \\
\hline D-Dimer (average) ng/ml & \multicolumn{2}{|c|}{$2765.45 \pm 169.11$} & \multicolumn{2}{|c|}{$1986.5 \pm 202.1$} & \multicolumn{2}{|c|}{$2014.3 \pm 108.04$} & \multicolumn{2}{|c|}{$2124.31 \pm 155.49$} & \multicolumn{2}{|c|}{$2451.5 \pm 174.5$} & $<0.001$ \\
\hline
\end{tabular}

patients, one patient presented with isolated straight sinus thrombosis, and one patient presented with internal jugular vein thrombosis.

Seventeen patients had peripheral thromboembolic manifestations; 9 patients (52.9\%) had deep venous thrombosis of the lower limb, 2 patients (11.8\%) had deep venous thrombosis of the upper limb, 5 patients (29.4\%) had lower limb ischaemia, and one patient (5.9\%) had upper limb ischaemia. All patients with deep venous thrombosis presented with edema of the affected

Table 2 Presenting symptoms

\begin{tabular}{|c|c|c|c|c|c|c|c|c|c|c|}
\hline \multirow[t]{2}{*}{ Presenting symptoms } & \multicolumn{2}{|c|}{$\begin{array}{l}\text { Pulmonary } \\
(n=56)\end{array}$} & \multicolumn{2}{|c|}{$\begin{array}{l}\text { Cerebral } \\
(n=32)\end{array}$} & \multicolumn{2}{|c|}{$\begin{array}{l}\text { Peripheral } \\
(n=17)\end{array}$} & \multicolumn{2}{|c|}{$\begin{array}{l}\text { Abdominal } \\
(n=19)\end{array}$} & \multicolumn{2}{|c|}{$\begin{array}{l}\text { Total } \\
(n=124)\end{array}$} \\
\hline & $N$ & $\%$ & $n$ & $\%$ & $n$ & $\%$ & $n$ & $\%$ & $n$ & $\%$ \\
\hline Fever & 56 & 100 & 18 & 56.25 & 12 & 70.6 & 15 & 78.9 & 101 & 81.5 \\
\hline cough & 49 & 87.5 & 12 & 37.5 & 6 & 35.3 & 4 & 21 & 71 & 57.3 \\
\hline Shortness of breath & 52 & 92.8 & - & - & 11 & 64.7 & 4 & 21 & 84 & 67.7 \\
\hline Chest tightness & 48 & 85.7 & 10 & 31.25 & - & - & - & - & 58 & 46.8 \\
\hline ECG changes & 37 & 66 & - & - & - & - & - & - & 37 & 29.8 \\
\hline Abdominal pain & 14 & 25 & 5 & 15.6 & - & - & 18 & 94.7 & 37 & 29.8 \\
\hline Diarrhea & - & - & 2 & & - & - & 8 & 42.1 & 10 & 8.1 \\
\hline Intestinal obstruction & - & - & - & - & - & - & 2 & 10.5 & 2 & 1.6 \\
\hline Loss of consciousness & - & - & 8 & 25 & - & - & - & - & 8 & 6.5 \\
\hline Motor weakness & - & - & 16 & 50 & - & - & - & & 16 & 12.9 \\
\hline Sensory loss & - & - & 5 & 15.6 & - & - & - & - & 5 & 4.0 \\
\hline Headache & 18 & 32.1 & 12 & 37.5 & - & - & - & - & 30 & 24.2 \\
\hline Limb edema & - & - & - & - & 11 & 64.7 & - & - & 11 & 8.9 \\
\hline Acute claudicating pain & - & - & - & - & 6 & 35.3 & - & - & 6 & 4.8 \\
\hline
\end{tabular}




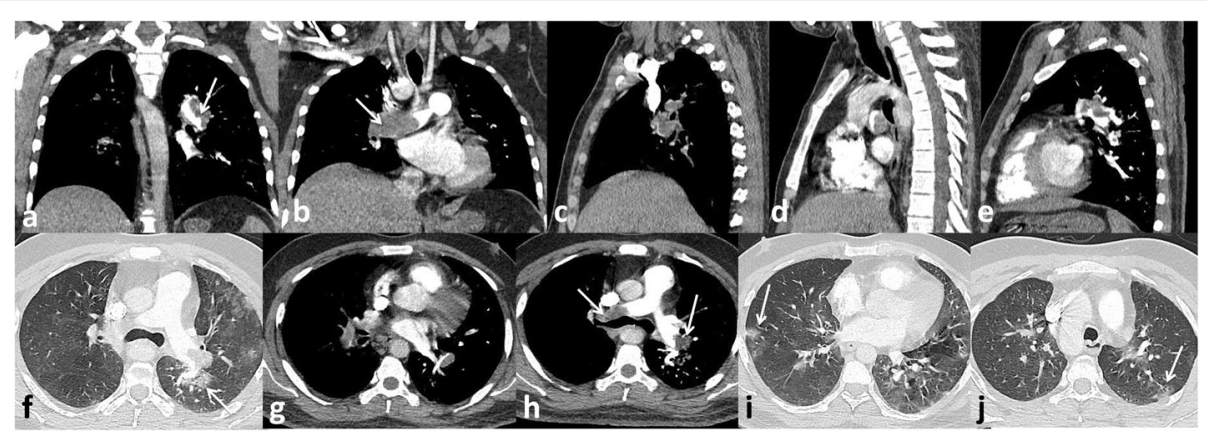

Fig. 3 Male patient, 32 years old. Pulmonary embolism at the main pulmonary arteries (white arrows $\mathbf{a}$, $\mathbf{b}$, and $\mathbf{h}$ ), ground-glass opacities of COVID-19 infection (white arrows $\mathbf{f}$ and $\mathbf{i}$ )

limb (Table 2). Eleven patients (91.7\%) of peripheral thromboembolic manifestations presented within the first week of admission.

Nineteen patients had abdominal thromboembolic manifestation; 17 venous thrombosis (89.5\%) and 2 arterial embolism (10.5\%). The most presenting symptom was abdominal pain (18 patients 94.7\%). Isolated superior mesenteric vein thrombosis was detected in 4 patients (21\%), isolated portal vein thrombosis occurred in 3 patients (15.8\%), isolated inferior vein thrombosis was detected in 1 patients (5.3\%), and combination of more than one vein thrombosis was detected in 9 patients (47.4\%). Arterial thrombosis was detected in the superior mesenteric artery in 2 patients (10.5\%), and both presented with bowel ischaemia and intestinal obstruction (Table 2).

\section{Discussion}

The coagulopathy that goes with COVID-19 has gained increasing interest recently. The International Society of Thrombosis and Haemostasis reported that patients with severe coronavirus disease 2019 (COVID-19) have fulminant activation of coagulation and consumption of coagulation factors [13].

In our study, we found 124 patients (about 10\%) with thromboembolic manifestations out of 1245 Covid-19positive patients, $68.5 \%$ of them were admitted to the ICU. The rate of thromboembolism reported in the literature is variable. Some studies have reported thromboembolic rates in the range of $20-30 \%$ while others have reported rates as high as $40-70 \%$ [14]. The number of patients with thromboembolic manifestations in our study was less than that of Klok et al. [3] who observed thrombotic complications in $31 \%$ of ICU patients in a multicenter cohort of 180 patients admitted to the ICU of three Dutch hospitals, and that difference was due to the specific group of patients that they studied as all patients were in the ICU.

The presence of hypercoagulation and thromboembolic complications had been noted to correlate with disease severity and ICU admission [14]. In our study, 85 patients $(68.5 \%)$ were admitted to the ICU.

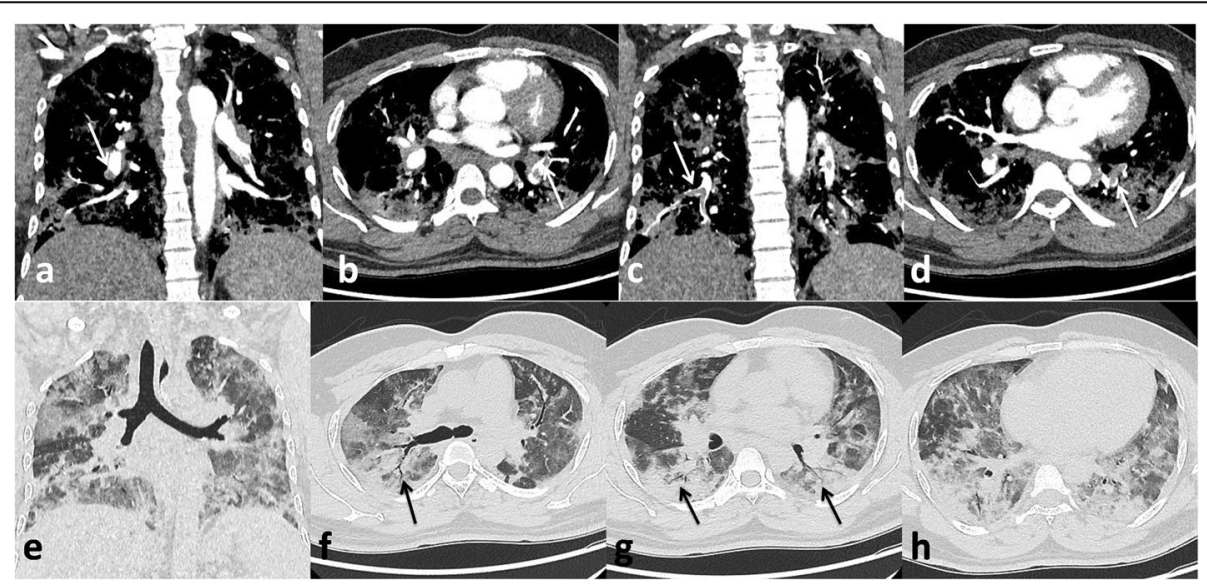

Fig. 4 Male patient, 33 years old. Pulmonary embolism at segmental pulmonary arteries (white arrows $\mathbf{a}, \mathbf{b}, \mathbf{c}, \mathbf{d}$ ), bilateral consolidation patches of COVID-19 infection with air bronchogram (black arrows $\mathbf{f}$ and $\mathbf{g}$ ) 


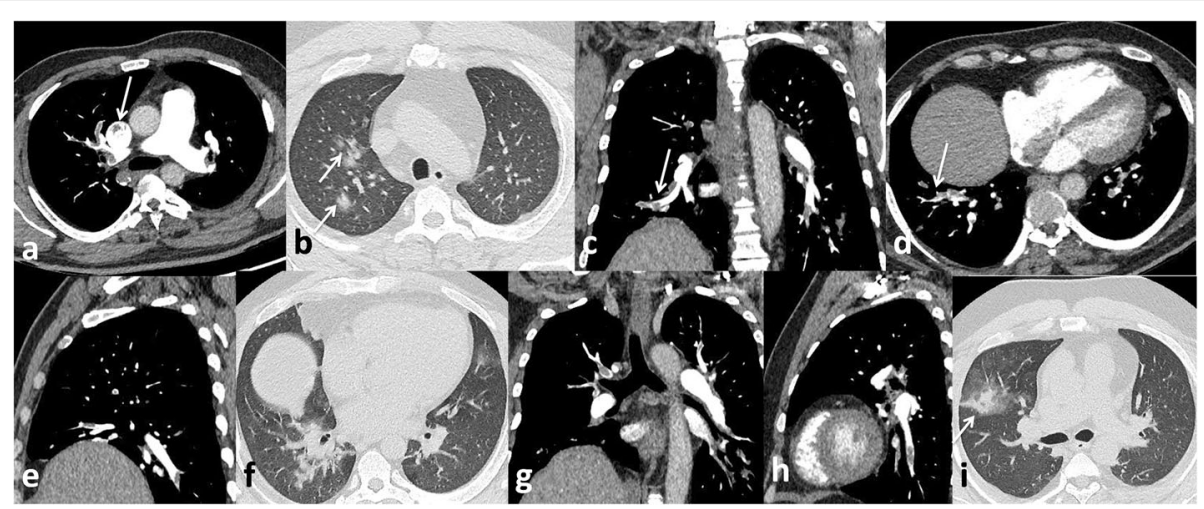

Fig. 5 Male patient 52 years old, pulmonary embolism in right main pulmonary artery (white arrow in a), segmental artery (white arrow in c), andsubsegmental artery (white arrow in $\mathbf{d}$ ), COVID-19 consolidation (white arrows in $\mathbf{b}$ and $\mathbf{i}$ )

In the current study, pulmonary embolism was the most common complication presented in 56 patients (45.2\%) that was similar to Grillet et al. [15] who stated that pulmonary embolism is the most common thromboembolic complication of COVID-19; it has been presented radiologically in up to $30 \%$ of patients with COVID-19 on pulmonary CT angiography and in $14 \%$ of ICU patients diagnosed with COVID-19 pneumonia Figs. 3, 4 and 5.

In a meta-analysis conducted by Xiong et al. [16], they found that prothrombin time and D-dimer levels were significantly higher in patients with severe COVID-19 than in those with the mild disease. Lorant et al. [17] stated that COVID-19 patients with pulmonary embolism have higher D-dimer levels than those without pulmonary emboli and are more likely to be admitted to the ICU. They also reported that D-dimer $>2660 \mathrm{ng} / \mathrm{mL}$ has $100 \%$ sensitivity and $67 \%$ specificity for pulmonary embolism diagnosis prediction in COVID-19 patients, and that was the same in our study which found that highest D-dimer average value was found in patients with pulmonary embolism (average $2765.45 \pm 169.11$ ).

As a complication of pulmonary embolism, the lung infarction is rare due to the dual arterial supply of the lung, but it has been described in COVID-19 patients. On CT, lung infarction appears as ground-glass opacities in the early phases in unobstructed lung zones that represents pulmonary haemorrhage and peripheral wedgeshaped pulmonary consolidation $[18,19]$.

Therefore, the radiological findings of lung infarction from pulmonary embolism should be differentiated from GGO as well as consolidations of the COVID-19 pneumonia that may also show reverse a halo sign in about $4 \%$ of patients as this will positively impact the patient management. In non-enhanced CT, the presence of peripheral lung opacities with a reverse halo sign, dilatation of pulmonary trunk, and/or increased cardiac volume (particularly, enlargement of the right cardiac chamber) indicate risk of $\mathrm{PE}$ and may aid in the decision to perform CT pulmonary angiography to confirm or exclude pulmonary embolism

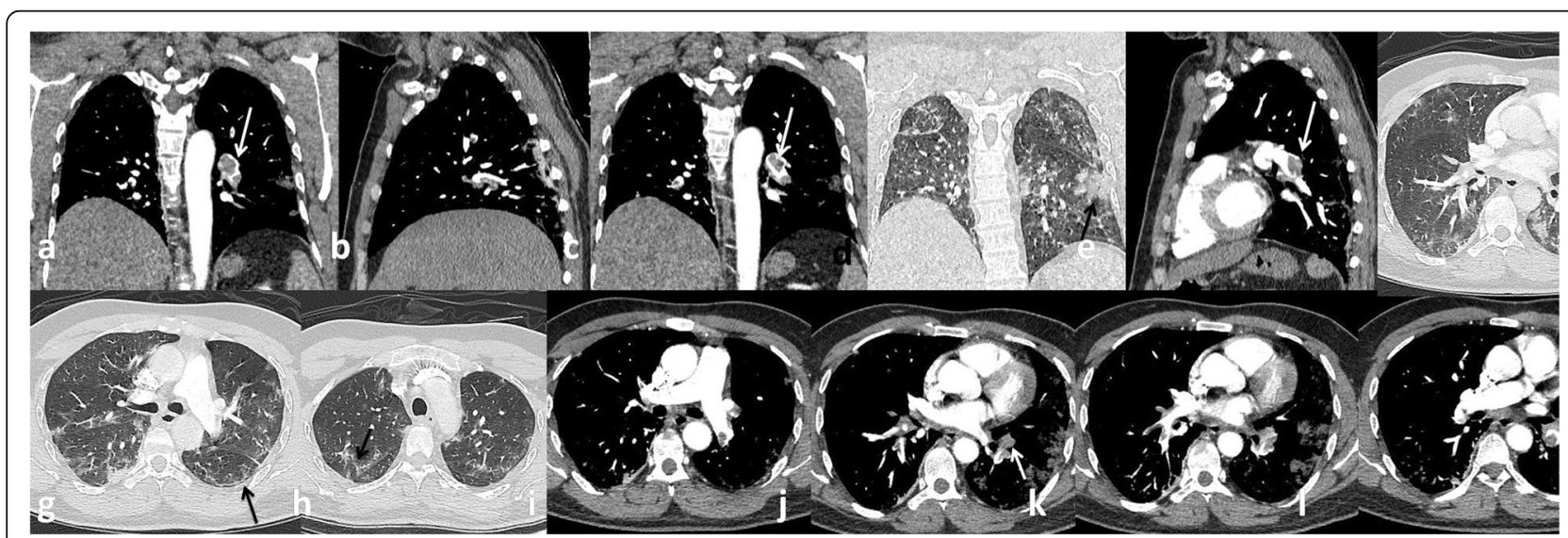

Fig. 6 Male patient 43 years old with pulmonary emoblism at left main pulmonary artery (white arrows in a, c, e), subsegmental artery (white arrow in $\mathbf{j}$ ), area of pulmonary infarction (black arrow in $\mathbf{d}$ ), COVID-19 infection manifestations (black arrows in $\mathbf{f}, \mathbf{g}, \mathbf{h}$ ) 


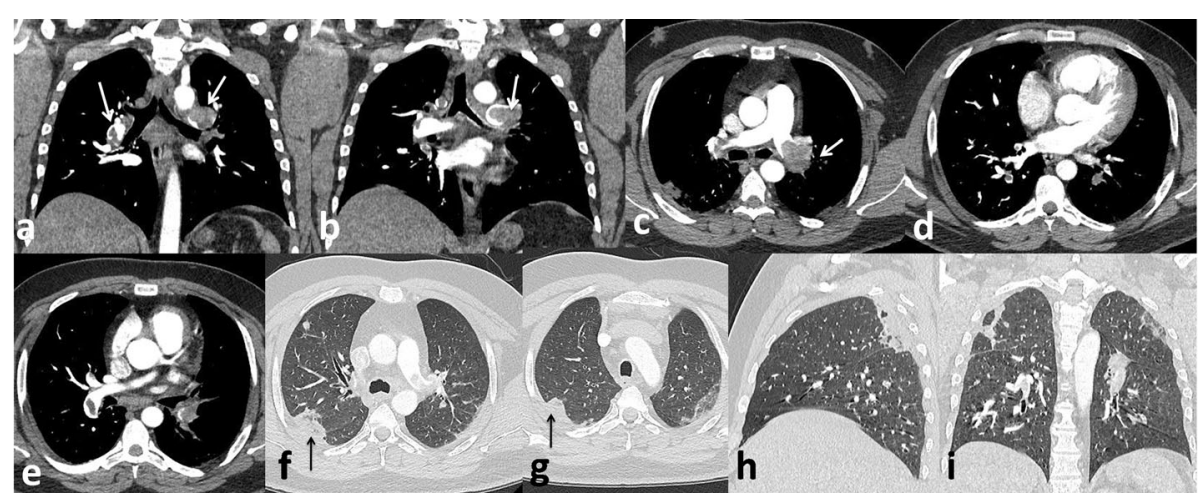

Fig. 7 Male patient 63 years old. Pulmonary embolism at main pulmonary arteries (white arrows in $\mathbf{a}, \mathbf{b}, \mathbf{c}$ ). Peripheral wedge shaped consolidation may represent pulmonary infarction black arrows in ( $\mathbf{f}$ and $\mathbf{g}$ )

[20]. Clinical parameters including highly elevated D-dimer levels, haemoptysis, and/or sudden worsening of respiratory function or chest pain should also be considered [21].

We have identified 14 patients with radiological findings that favor the evidence of lung infarction more than the classic GGO and consolidations of COVID-19. These patients had higher D-dimer levels with dilatation of the affected segment of the pulmonary artery. The peripheral wedge-shaped consolidation was associated with thrombus of the related subsegmental artery (Figs. 6 and 7).

In the current study, we reported 32 patients with acute cerebrovascular manifestations, 27 (65.6\%) of them had evidence of vascular occlusion (arterial in $18 \mathrm{pa}$ tients Fig. 8 and venous sinus thrombosis in 9 patients Fig. 9) and 7 (21.88\%) had haemorrhagic stroke. These results are close to those of $\mathrm{Li}$ et al. [22] who reported cerebrovascular manifestations for (6\%) of 221 COVID-19 patients in a retrospective case series from Wuhan: $5 \%$ patients developed ischaemic strokes, $<1 \%$ intracerebral haemorrhage, and $<1 \%$ cerebral venous sinus thrombosis. However, the number of patients in our results was much less than the patients of Benussi et al. [23] who reported that (77\%) of 55 COVID-19 patients admitted to one neurology unit with cerebrovascular disease, 35 of them had ischaemic stroke, three patients had haemorrhagic stroke, and five had transient ischaemic attacks. This difference is likely due to specific patient's group that they studied as it was specialized neurology unit.

In our study, five patients (12.5\%) presented with small infarcts identified only on MRI with no definite vascular involvement. Figures 10 and 11 Kandemirli et al. [24] reported that $44 \%$ of ICU COVID-19 patients with neurological symptoms showed abnormal findings on brain MRI studies.

In a study done by Wichmannet et al. [25] on autopsy series, they found unsuspected deep vein thrombosis in the majority of COVID-19 patients, and that pulmonary embolism was the cause of death; also, Goldman et al. [26] stated that there is high incidence of arterial thrombosis in COVID-19 patients presenting with ischaemic

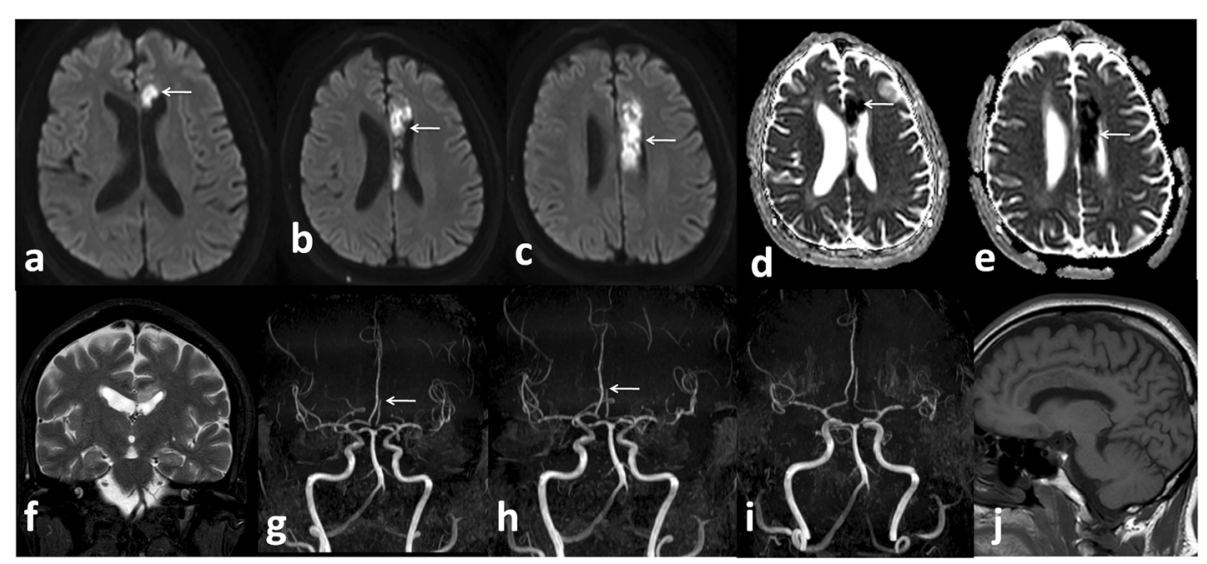

Fig. 8 Female patient 54 years old. Left ACA territory infarction. DWI (white arrows in $\mathbf{a}, \mathbf{b}, \mathbf{c}$ ), ADC map (white arrows in $\mathbf{d}$ and $\mathbf{e}$ ), MRA defective A3 segment of left ACA (white arrows in $\mathbf{g}$ and $\mathbf{h}$ ) 


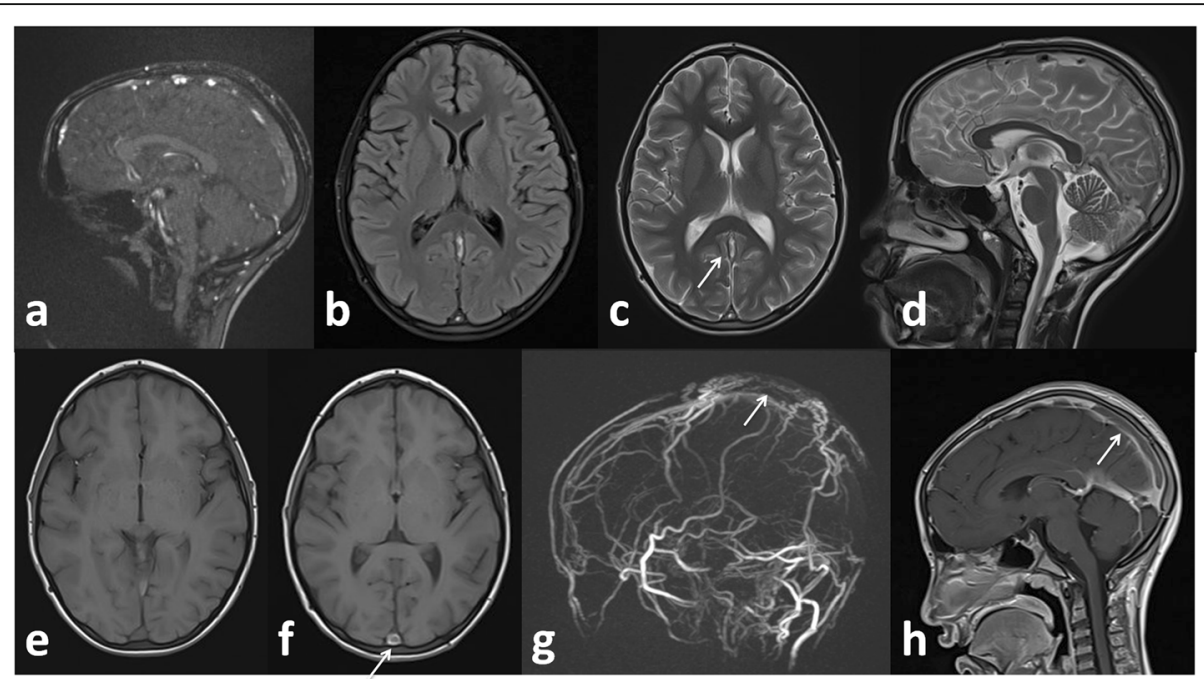

Fig. 9 Female patient 42 years old. Superior sagittal sinus thrombosis (white arrows in $\mathbf{c}$, $\mathbf{f}$ ), filling defect in MRV (white arrow in $\mathbf{g}$ ) and post contrast image (white arrow in $\mathbf{h}$ )

leg symptoms (100\% of cases in their cohort). They found that lower extremity arterial thrombosis associated with COVID-19 is characterized by greater thrombus burden and increased rate of amputation and death. In our study, 17 patients had peripheral thromboembolic manifestations, 9 patients (52.9\%) had deep venous thrombosis of the lower limb, 2 patients $(11.8 \%)$ had deep venous thrombosis of the upper limb, 5 patients (29.4\%) had lower limb ischaemia Fig. 12, and one patient (5.9\%) had upper limb ischaemia.

Bhayana et al. [27], in their study, described radiological abnormalities detected on abdominal $\mathrm{CT}$ in about
$42 \%$ of COVID-19 patients as large or small bowel thickening, pneumatosis intestinale, portal vein gas, or bowel perforation, and also bowel ischaemia or necrosis was demonstrated in some of these patients who underwent surgery. In addition, acute infarction in abdominal solid organs was demonstrated in $4.8 \%$ of patients.

In the current study, we reported 19 cases with gastrointestinal thromboembolic complications, 17 venous thrombosis (89.5\%) and 2 arterial embolism (10.5\%). The most presenting symptom was abdominal pain in 18 patients $(94.7 \%)$. Isolated superior mesenteric vein thrombosis was detected in 4 patients $(21 \%)$, isolated portal

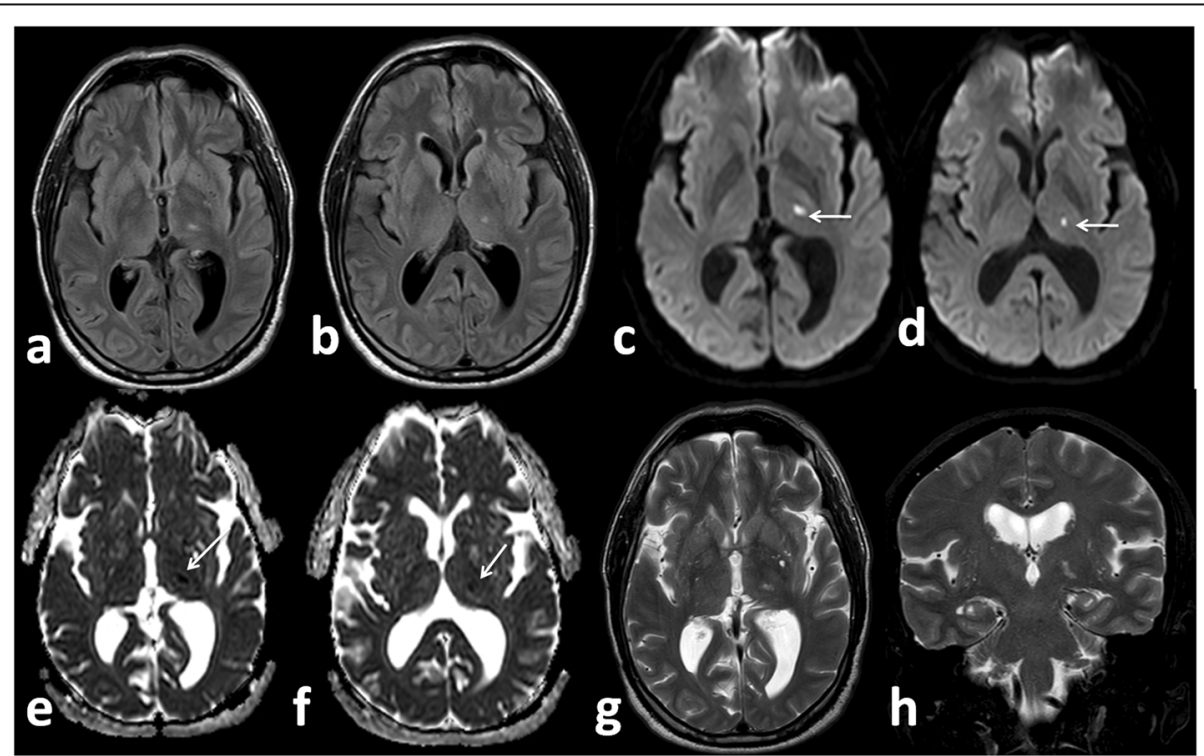

Fig. 10 Male patient 48 years old presented with sensory loss. Left thalamic infarction. DWI (white arrow in c and d), ADC map (white arrows in e and $\mathbf{f}$ ) 


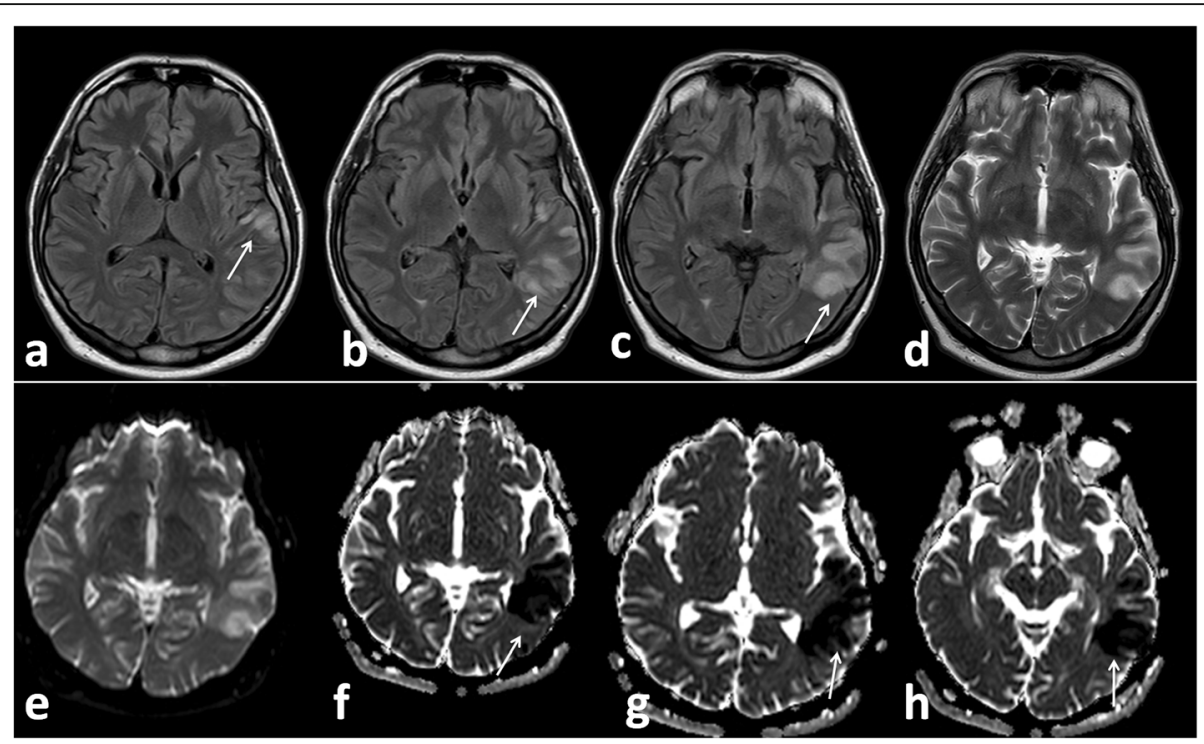

Fig. 11 Female patient 62 years old presented with coma. Left temporal infaction (white arrows in $\mathbf{a}, \mathbf{b}$, c, d) restricted diffusion in ADC map (white arrows in $\mathbf{f}, \mathbf{g}, \mathbf{h}$ )

vein thrombosis occurred in 3 patients (15.8\%), isolated inferior vein thrombosis was detected in 1 patients (5.3\%), and combination of more than one vein thrombosis was detected in 9 patients (47.4\%) Fig. 13. Arterial thrombosis was detected in the superior mesenteric artery in 2 patients $(10.5 \%)$ and both of them presented with bowel ischaemia and intestinal obstruction.

\section{Conclusion}

The incidence of thromboembolic complications in COVID-19 patients is relatively high, and the appropriate mechanism of these complications is the procoagulant pattern and the endothelial thromboinflammatory syndrome, which may result in multisystemic thrombotic disease.

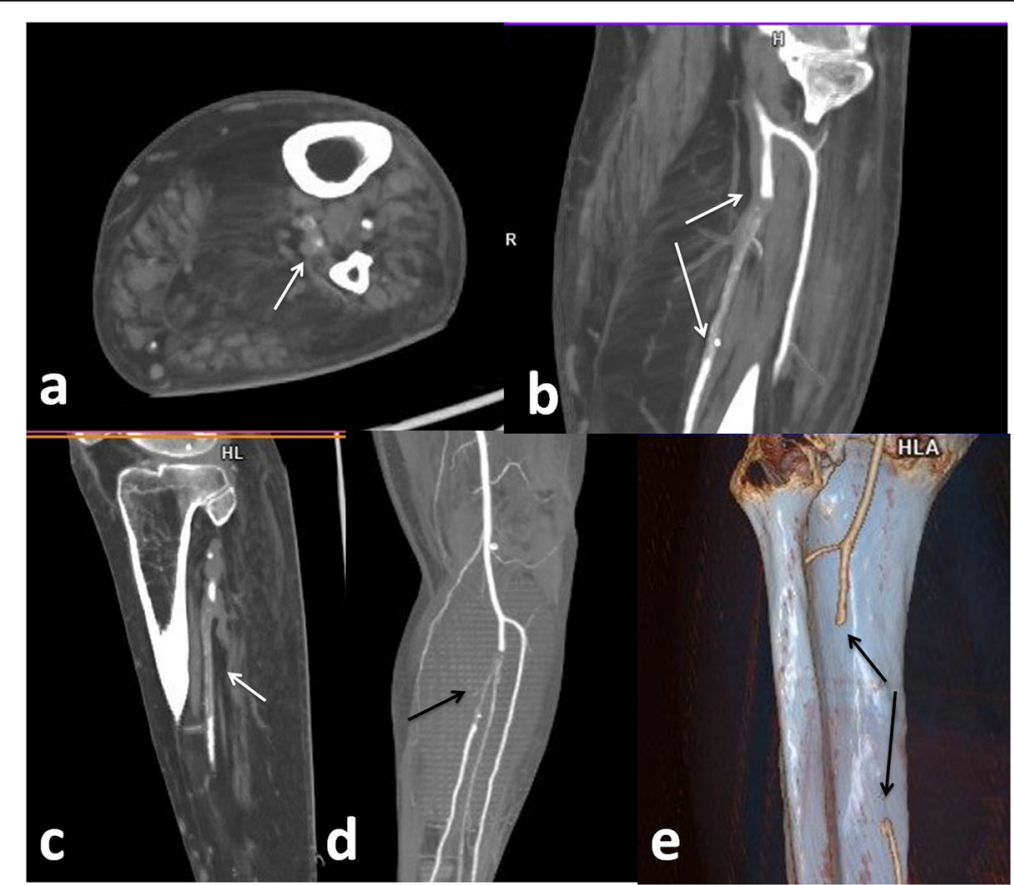

Fig. 12 Female patient 52 years old. Acute thormbus of proximal seep peroneal artery (white arrows in a,b,c), CTA (black arrow in $\mathbf{d}$ ), 3D reconstructed image (filling defect black arrows in e) 


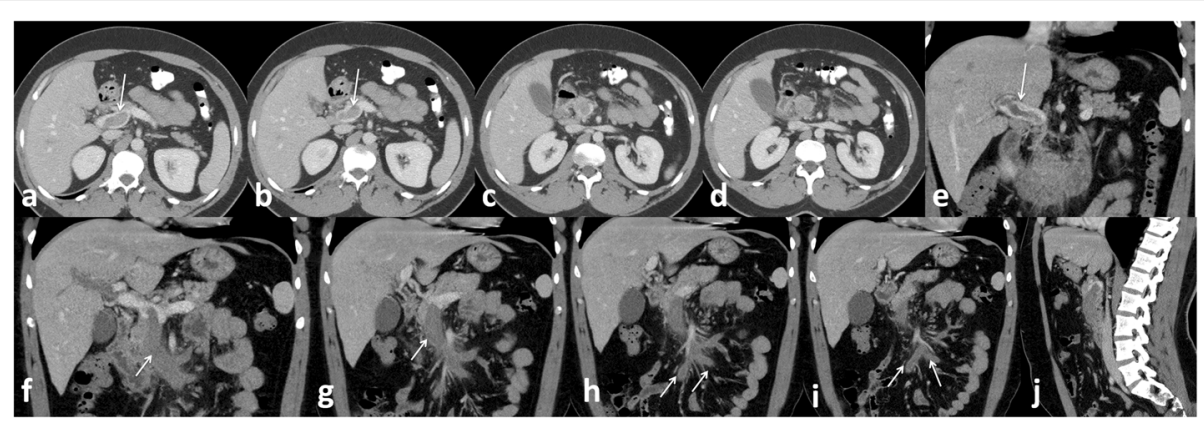

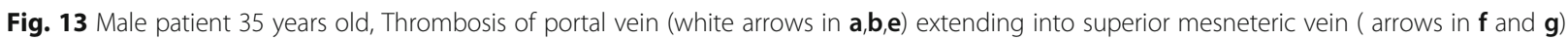
and its territories (arrows in $\mathbf{h}$ and $\mathbf{i}$ )

In our study, the D-dimer level was more than 2600 $\mathrm{ng} / \mathrm{mL}$ in 83 patients including all 56 patients with pulmonary emboli. So, in patients with high D-dimer levels on hospital admission or sudden clinical worsening, CT pulmonary angiography should be done to exclude pulmonary embolism

Also risk factors (diabetes, obesity, heavy smoking), clinical parameters, including haemoptysis, sudden worsening of respiratory function, acute abdomen and peripheral limb edema, or chest pain should raise the suspicions of thromboembolic complications.

So, in addition to the crucial golden role of CT chest for assessment of COVID-19 pneumonia, other imaging modalities (Duplex study, CT angiography, and MRI brain) are also important for the assessment of the thromboembolic complications, such as pulmonary emboli, cerebrovascular strokes, mesenteric vascular ischaemia, and peripheral ischaemia, especially in patients with high D-dimer levels and those with sudden clinical deterioration.

\section{Abbreviations \\ COVID-19: Coronavirus disease 2019; ACE2: Angiotensin-converting enzyme 2; CT: Computed tomography; ICU: Intensive care unit; MRI: Magnetic resonance imaging; DWl: Diffusion weighted imaging}

\section{Acknowledgements}

We would like to thank all people who helped us in this work including the $\mathrm{CT}$ and MRI technicians.

\section{Authors' contributions}

SO made substantial contribution to the main research idea; design of the work; acquisition, analysis, and interpretation of the data; writing of the manuscript, and revision of the work. RH contributed in the analysis of the data, interpretation of the results, summarization of the discussion, and final revision of the manuscript. AM made substantial contribution to the main research idea; design of the work; acquisition, analysis, and interpretation of the data; and drafting and revision of the work. The authors have read and approved the final manuscript.

\section{Funding}

Self-funding.

Availability of data and materials All data and materials are available.

\section{Declarations}

Ethics approval and consent to participate

The study protocol was approved by the local Ethics Committee. All study procedures were performed in accordance with the ethical standards laid down in the 1964 Declaration of Helsinki and its later amendments. The ethics committee's reference number is 9/2020RAD4.

\section{Consent for publication}

A written consent was taken from all patients prior to the study for publication.

\section{Competing interests}

The authors declare that they have no competing interest.

Received: 16 October 2020 Accepted: 22 February 2021

Published online: 08 April 2021

\section{References}

1. Tang N, Bai H, Chen X, et al. Anticoagulant treatment is associated with decreased mortality in severe coronavirus disease 2019 patients with coagulopathy. J Thromb Haemost 2020, https://doi.org/https://doi.org/1 0.1111/jth.14817.

2. Wang T, Chen R, Liu C, et al. Attention should be paid to venous thromboembolism prophylaxis in the management of COVID-19. Lancet Haematol 2020, https://doi.org/https://doi.org/10.1016/S2352-3026(20)301 09-5. S2352- 3026(20)30109-5.

3. Klok FA, Kruip MJHA, Van M et al (2020) Incidence of thrombotic complications in critically ill ICU patients with COVID-19. Thromb Res S00493848(20):30120-30121

4. Cui S, Chen S, Li X, et al. Prevalence of venous thromboembolism in patients with severe novel coronavirus pneumonia. J Thromb Haemost 2020, https://doi.org/https://doi.org/10.1111/jth.14830.

5. Hamming I, Timens W, Bulthuis M et al (2004) Tissue distribution ofACE2 protein, the functional receptor for SARS coronavirus: a first step in understanding SARS pathogenesis. J Pathol 203:631-637 Cross Ref Medline

6. Li WH, Moore MJ, Vasilieva NY et al (2003) Angiotensin-convertingenzyme 2 is a functional receptor for the SARS coronavirus. Nature 426:450-454 Cross Ref Medline

7. Zou X, Chen K, Zou J, Han P, et al. Single-cell RNA-seq data analysis on the receptor ACE2 expression reveals the potential risk of different human organs vulnerable to 2019-nCoV infection. Front Med. 2020;http://dx.doi. org/https://doi.org/10.1007/s11684-020-0754-0.

8. Chen J, Wang X, Zhang S, et al. Findings of acute pulmonaryembolism in COVID-19 patients. 2020. Available at SSRN: https://ssrn.com/abstract=354 8771 or https://doi.org/102139/ssrn3548771 Google Scholar.

9. Algahtani H, Subahi A, Shirah B (2016) Neurological complications of Middle East respiratory syndrome coronavirus: a report of two cases and review of the literature. Case Rep Neurol Med 2016:3502683

10. Chen N, Zhou M, Dong X et al (2020) Epidemiological and clinical characteristics of 99 cases of 2019 novel coronavirus pneumonia in Wuhan, China: a descriptive study. Lancet 395:507-513 
11. Han $H$, Yang L, Liu R, et al. Prominent changes in blood coagulation of patients with SARS-CoV-2 infection. Clin Chem Lab Med 2020; Epub ahead of print. https://doi.org/https://doi.org/10.1515/cclm-2020-0188

12. Bikdeli B, Madhavan MV, Jimenez D et al (2020) COVID-19 and thrombotic or thromboembolic disease: implications for prevention, antithrombotic therapy, and follow-up. J Am Coll Cardiol S0735-1097(20):35008-35007

13. Kaur P, Qaqa F, Ramahi A, et al. Acute upper limb ischemia in a patient with COVID-19. Hematol Oncol Stem Cell Ther 2020. https://doi.org/https:// doi.org/10.1016/j.hemonc.2020.05.001, Submitted for publication.

14. Malas M, Naazie I, Elsayed N et al (2020) Thromboembolism risk of COVID19 is high and associated with a higher risk of mortality: a systematic review and meta-analysis. E Clin Med 29-30:1-9

15. Grillet F, Behr J, Calame P et al (2020) Acute pulmonary embolism associated with COVID-19 pneumonia detected by pulmonary CT angiography. Radiology:201544. https://doi.org/10.1148/radiol.2020201544

16. Xiong $M$, Liang $X$, Wei $Y$. Changes in blood coagulation in patients with severe coronavirus disease 2019 (COVID-19): a meta-analysis. Br J Haematol 2020. https://doi.org/https://doi.org/10.1111/bjh.16725, Submitted for publication.

17. Lorant LI, Delabranche X, Severac F et al (2020) Acute pulmonary embolism in COVID-19 patients on CT angiography and relationship to D-dimer levels. Radiology:201561. https://doi.org/10.1148/radiol.2020201561

18. Lax SF, Skok K, Zechner P, et al. Pulmonary arterial thrombosis in COVID-19 with fatal outcome: results from a prospective, single-center, clinicopathologic case series. Ann Intern Med (14 May 2020), https://doi. org/10.7326/M20-2566

19. Cha SI, Shin KM, Lee J et al (2012) Clinical relevance of pulmonary infarction in patients with pulmonary embolism. Thromb Res 130(3):e1-e5. https://doi. org/10.1016/j.thromres.2012.03.012

20. Torres P, Mancano A, Zanetti G et al (2020 Apr) Multimodal indirect imaging signs of pulmonary embolism. Br J Radiol 93(1108):20190635. https://doi. org/10.1259/bjr.20190635

21. Moreira B, Santana P, Zanetti G, Marchiori E (2020) COVID-19 and acute pulmonary embolism: what should be considered to indicate a computed tomography pulmonary angiography scan? Rev Soc Bras Med Trop 53: e20200267. https://doi.org/10.1590/0037-8682-0267-2020

22. Li Y, Wang M, Zhou Y, et al. Acute cerebrovascular disease following COVID19: a single center, retrospective, observational study. 2020. https://media. tghn.org/medialibrary/2020/06/Li_2020_Preprint_

23. Benussi A, Pilotto A, Premi E, et al. Clinical characteristics and outcomes of inpatients with neurologic disease and COVID-19 in Brescia, Lombardy, Italy. Neurology 2020; published online May 22. https://doi.org/10.1212/WNL. 0000000000009848.

24. Kandemirli SG, Dogan L, Sarikaya ZT et al (2020) Brain MRI findings in patients in the intensive care unit with COVID-19 infection. Radiology 297: E232-E235.

25. Wichmann D, Sperhake JP, Lütgehetmann M et al (2020) Autopsy findings and venous thromboembolism in patients with COVID-19: a prospective cohort study (published online ahead of print, 2020). Ann Intern Med. https://doi.org/10.7326/M20-2003

26. Goldman I, Kenny Y \& Scheinfeld M. Radiology Published Online: Jul 16 2020 https://doi.org/https://doi.org/10.1148/radiol.2020202348

27. Bhayana R, Som A, Li M et al (2020) Abdominal imaging findings in COVID19. Preliminary observations. Radiology:201908. https://doi.org/10.1148/ra diol.2020201908

\section{Publisher's Note}

Springer Nature remains neutral with regard to jurisdictional claims in published maps and institutional affiliations.

\section{Submit your manuscript to a SpringerOpen ${ }^{\circ}$ journal and benefit from:}

- Convenient online submission

- Rigorous peer review

- Open access: articles freely available online

High visibility within the field

- Retaining the copyright to your article

Submit your next manuscript at $\boldsymbol{\nabla}$ springeropen.com 